\title{
Authentic Management and Emotionally Intelligent Leaders versus Conjectural Management and Conjectural Leaders
}

\author{
Doinița CIOCÎRLAN ${ }^{1}$
}

\begin{abstract}
Even though, from a theoretical standpoint, professional management (considered authentic management) is a truism, the economic practice often proves the opposite. We need to admit that, in recent years, we have witnessed an alarming increase in the number of conjectural managers, of conjectural leaders, a phenomenon with negative effects on the economic, financial and managerial performance of the organizations they run, whether they operate in the public or the private sector. The negative effects are certainly not limited to the respective organizations, but propagate at society level. An authentic manager is a person who has managerial competences both in the domain they manage, proven by means of having graduated from specialized educational programs of certain higher education institutions (certified by means of graduation diplomas in compliance with the law, which warrants that their owners acquired the respective program's general and specialized competences), and, also, by means of the results of their exerting managerial prerogatives in actual practice (managerial performance indicators and implicitly the economic, financial and managerial performance indicators of the organization/management structure they run, the supporting documentation mainly being the management agreement, the respective manager's institutional assessments, the management reports, the audit reports and the organization's financial-accounting documents during the management term/agreement).

The objective of the research is to create a tool which makes it possible to quantify managerial performance and to design a new situational management based on correlating result indicators with organizational and managerial competence.
\end{abstract}

KEYWORDS: management, leadership, organizational theories, organizational competence, emotional intelligence.

JEL CLASSIFICATION: $M 10, M 19$

\section{INTRODUCTION}

At present, there is no area of life or of economic and social practice which is not concerned with the vast and highly complex issue of management, regardless of how it may be defined: as management or as leadership. The manager and the leader have become, over time, the central figure in any type of organization: industrial, political, military, administrative, commercial, sanitary, sportive, cultural, etc. Bennis and Nanus (2000) stated in their work that the "driving force behind successful organizations is the management capacity", and Peter Drucker (1973) extended the role and importance of management to the level of society, arguing that "the dreams, values and even survival of society in developed countries will eventually depend on its leaders' competence, dedication and value." (Zlate, 2007, p.1).

\footnotetext{
${ }^{1}$ Romanian - American University, Bucharest, Romania, doinita.ciocirlan@rau.ro
} 
The definitions of management vary from one philosophic trend to another, from one school to another, according to the background training of the researchers - psychology, economics or management. In the process of conceptual substantiation, some authors emphasize the manager's/leader's abilities, others emphasize personality traits or influence relationships. We also encounter the cognitive versus emotional orientation, where the separation between management and leadership is made more profoundly, the individual versus group orientation, or, from the social psychology perspective, the emphasis on ego versus the emphasis on collective interests.

We consider it important to separate the concepts of management and leadership, placing them in a relationship of the type whole - part, in the sense that leadership must be a part of management. The premise we start from is that management has a degree of formalization, regardless of whether the management process is performed at individual level (manager, as managing position, differentiated along the three management levels) or at team level (case in which we refer to management structures of the type Management Board, Board of Directors, etc., in compliance with the legislation regulating each and every domain). If management takes two forms, namely individual and collective ones, leadership is exclusively individual. We cannot consider that a management structure such as the Management Board is synonymous with the respective organization's leadership, defined in this context as, most probably, the sum of its members' leadership skills. This is conceptually erroneous. From an individual perspective, there may be similarity in terms of the president of such structure, but he/she usually is the president of the respective organization as well, vested with formal authority, on the basis of a management agreement, in compliance with the legislation regulating the respective domain, or, from a collective perspective, this is defined as top management team. At decision-making level, strategic decisions are certainly made (or should be made democratically) with simple majority of voters at the level of this management structure, yet, in this situation, we are not referring to leadership, but to strategic management.

We must consider the fact that the manager has formal authority, legitimate power, whereas the leadership position is not present in any organizational chart, in any description of roles, in any job description, in any individual employment agreement, in any normative act, at least nationally (Classification of Occupations in Romania, COR, revised according to the International Standard Classification of Occupations, ISCO-88 is an argument supporting this statement). We certainly consider it essential that the manager should have leader skills (charisma, vision, courage, etc.) so that, beyond the administrative management which defines their role and the mission they have at organizational level, they may achieve a level of performance by means of what specialists call psychological management, or capacity to influence others to do what the manager-leader knows that must be done. We share the opinion of authors who state that management is administrative, while leadership is psychological, and we consider it essential to add that leadership emotionally activates the individual in general and the organizational individual in particular, that leadership triggers emotion and a certain collective mood which may be positive, directed towards ethical actions and behaviors, compatible with social norms (in this case, we are referring to moral leadership), or, on the contrary, emotions and mood which aim towards actions and behaviors that are contrary to ethical principles, having negative effects at social and organizational level, which cannot be ignored under any circumstances. Moreover, there are no defined/set limits beyond which psychological leadership, influencing others is good (directed towards achieving the targeted results while observing ethical principles), or an act of glory, of performance and not manipulation (undesirable situation). 
Consequently, in this research we will refer to leadership assimilated to management, considering that management is authentic only if it includes in its structure the moral leadership part as well. And, without minimizing the importance of the other management levels, we will focus on top management, which is the level that formulates the strategic vision, the only management level with formal authority to make strategic decisions, to direct organizational culture, to ratify and implement the employment code of ethics and, at the same time, the level which is directly accountable for achieving the organization's mission, the goal for which it was set up. As to the manager, we will define it in terms of job-related and managerial competence, leadership skills, education, emotional intelligence and its own stated, internalized and proven system of values. And we will try to identify in the top manager's competence - defined by means of a set of managerial competences, job-related competences (technical or domain-specific ones), transversal competences, ethical and moral competence, emotional and social competences (research in the field proves that, for management position, about $90 \%$ of the competences needed for success are emotional or social ones), leadership skills, personal development capacity, (academic, emotional and interpersonal) intelligence, education - a determining factor for the longevity of the high performing organization.

\section{THEORIES ON ORGANISATIONS, MANAGEMENT AND LEADERSHIP IN THE SPECIALSIED LITERATURE: A LITERATURE REVIEW}

Society as a whole is made up of a coherent system of organizations which achieve certain goals of society. According to DEX (1998) [n.t. Romanian Language Explanatory Dictionary], "the organization is an association of people with shared concepts or interests, brought together in compliance with a regulation or statute, in order to perform organized activity".

From the perspective of social psychology, the concept of organization may be defined in terms of three levels, each with its specific approach (Cristea, 2015):

a) "The logical-principal level, which reveals the rationality rules which substantiate the systemic activities of human collectivities;

b) The functional-processual level, which reflects the dynamics of how the system of interactions unfolds in time, system by means of which the organization is set up, develops and is actively present in social life;

c) The structural-objectual level, which captures the palpable and stable system of interactions among the parts of the whole (individuals, groups);

d) The exorelational level, which captures the way in which the organization relates to the other sub-systems of global society and to the environment where it operates."

As palpable forms of systemic interactions among the members of a community, organizations cover all domains of society (educational, economic, administrative, legislative, political, cultural ones, etc.), they are self-regulating psycho-social systems which have certain common features and traits, regardless of their nature, and which essentially define them. Thus:

a) "They are constructed, deliberately and programmatically elaborated human ensembles in which systematic and orderly interactions are occurring on the basis of a precise interactional model: organizational chart, operational rules, control systems, etc.

b) They have clearly formulated objective, which all the members of the organization embrace, such objectives having a constitutive and legitimating role both for the 
internal structuring process, and for the organizational activity related to the completion of tasks.

c) They develop an internal structure which indicates positions, hierarchies and the functional relationships among them.

d) They have an internal differentiation of positions, functions, duties, roles and activities whereby the various elements of the shared objective are achieved; the differentiation is visible both horizontally, in the coordinate relationships among the parties, and vertically, in the subordinate relationships.

e) They display structural and functional dynamics, in close connection with the level of goals achievement, of the internal interpersonal relationships evolution and of the relationships with the external social environment.

f) They have certain degrees of freedom in connection with the states they may have, both at internal and at external level (organizational autonomy).

g) They maintain dynamic relationships with the external environment (institutions, other organizations, groups or individuals), in the context of a relative organizational and functional autonomy, but under the generic influence of certain institutions they belong to.

h) They develop multiple mechanisms of internal and external self-regulations, which confers them the quality of adaptive cybernetic systems." (Cristea, 2015)

Despite being difficult to systemize, organizational theories are found in the specialized literature under the following classification:

1. Classical theories - which approach the organization from the formal structure perspective, emphasizing the analysis alongside four important elements, namely: efficiency, the principles of functional hierarchy and authority, high performing organization structures and adequate control measures. (Zlate, 2008, p.2)

In the category of classical theories, there are: the scientific management theory (elaborated by Frederick Winslow Taylor), the theory of administrative management (initiated by Henri Fayol) and the bureaucracy theory (elaborated by Max Weber).

Classical theories may be considered relevant only in light of their contribution to the domain of formal organization, otherwise they are extremely limited, because they used the principle of management uniqueness and bureaucracy, but did not give importance, attention or consideration to the human resource, instead they placed "the decision-making power exclusively in the hands of the manager, who compels the subordinate to obey", all, obviously, in order to "achieve efficiency at any cost, even by way of sacrificing those who contribute to achieving it". (Zlate, 2008, p.2)

2. Neoclassical theories - which try to diminish the deficiencies of classical theories, thus granting a key role to the human resource and implicitly to the psycho-social phenomena which result from the interactions among individuals. Thus, we move from the analysis of the organizational chart to the study of the sociogram of the groups within the organizations, from the highly structured and technical approach to the organization to the informal, psychological approach thereof, to motivating employees, increasing their level of satisfaction, creating a positive organizational environment, decreasing conflicts between employees and employers.

The main neoclassical philosophical trends are: the human relations theory (created by George Elton Mayo), the sociometric theory (elaborated by Jacob Levy Moreno, born in Romania) and, in some authors' opinion (Zlate, 2008, p.2), the dynamics theory (created by Kurt Lewin).

The added value of neoclassical theories is, beyond any doubt, the inclusion of psychological and psycho-social variables in the equation of the organization's efficient 
operation and performance, yet, the approach balance threshold is exceeded and the consequence is the absolutization of psychological elements and not interpreting them from a relational perspective, in interaction with other elements which constitute the organization's internal and external environment. Consequently, these theories, despite their indisputable merits, are in the same limitation/limiting paradigm as classical theories, even though, this time at the opposite end, namely the area of psychological factors.

3. Modern theories - they are based on the concept of system, interpreting the organization as a whole dependent on and in interdependence with a variety of structures and processes (such as that of communication, the balancing of system mechanisms or decision-making). New concepts are introduced in the definition of the organization and of its structure, an actual progress being triggered by the implementation of the general theory of systems and cybernetics in the interpretation of organizational processes and phenomena. In modern theories, the organization is seen as a rational system, as natural system and as open system, each of the three aspects having a specific mechanism in place for efficient structuring and operation.

Zlate (2008:2) mentions three relevant modern theories, namely: "the technological or organizational sociology theory (which shifts the focus from the personal and interpersonal factors to impersonal and structural factors), the psychological or human resources theory (which reassesses the managers' behaviors according to the expectations their subordinates have from them and, more importantly, according to meeting the needs for people's social recognition and fulfillment) and the psycho-technological or sociotechnical theory (elaborated with an aim to balance the previous theories)". Scientific studies with impact on modern theories were performed by: Joan Woodward, Jay William Lorsch and Paul Roger Lawrence (the organizational sociology theory), Douglas Murray McGregor, James Gardner March, Herbert Alexander Simon and Chris Argyris (the human resources theory) and respectively Eric Lansdown Trist and Frederick Edmund Emery (the sociotechnical theory).

Modern theories certainly generated interest, triggering an outburst of ideas meant, on the one hand, to confirm their value and, on the other hand, to contribute to increasing it. The praiseworthy elements of these theories consist of formulating the following ideas, summarized by Zlate (2008:2) as follows: "(1) there are no universally valid organizational and management principles, but principles applicable or adapted to the technological, psychological and environmental requirements (which means that the same principles are unequally productive according to the context in which they operate); (2) organizational efficiency must not be approached abstractly, but from the perspective of the level of adequacy among the three categories of variables: technological, psychological, environmental."

4. Postmodern theories - they bring a fresh perspective by shifting from the organization as a system to placing it at the foreground of the organization and organizers' process. Cristea (2015) considers that "postmodernism uses the deconstruction method to make a critical analysis of various theories, in order to identify new coordinates based on which to understand the outstanding complexity of the organizational phenomenon", practically redefining the organizational person and their way of interpreting the world they live in.

In the same category, still under elaboration process, as Zlate (2008, p.2) synthesizes, there is the cognitive approach (elaborated by Karl Edward Weick who "focused on demonstrating the role of cognitive processes in constructing, reconstructing and supporting the organizations"), the psychoanalytical approach (which originates from the studies made by Elliott Jacques who "proposed the idea of collaborative intervention, opposed to the technological approach, as well as the idea of using a new method of analysis inspired by psychoanalysis, which was called socio-analysis, because it was meant 
to investigate social groups and not separate individuals"), and, respectively, the evolutionary approach (Benjamin Coriat, Olivier Weinstein and Jean-Michel Plane being among the researchers interested in the new philosophical trend in the organizationalmanagerial psychology). In the evolutionists' perspective, “the organization's driving force is not the profit, but the biological desire to survive, as any living being in the Darwinian theory of the evolution of the species. It proposes to study the organization's mechanisms of adapting to the environment, its capacity to learn and self-organize" (Zlate, 2007, p.1) apud (Plane, 2000)

We adopt the evolutionary theory, considering that the new construct is the "intelligent organization".

Regarding management, the concept is polysemic, on the one hand due to its inherent complexity, and, on the other hand, due to the fact that it has been the focus of the study, research and interest of specialists in various domains - economics, engineering, sociology, psychology, military sciences, etc. Historically speaking, theories that approach the issue of leadership and management have developed. There are philosophical trends especially in organizational psychology, which approach the leadership activity and the person who performs it (the leader). For many authors, at the crossroads of psychology and sociology, considered as social systems, organizations always involve an essential component, namely management, defined as "a set of activities, processes and functions, consisting of informing, organizing, planning, coordination and control, based on decisions, whereby the accurate, coherent, viable and efficient operation of various social structures is ensured: institutions, organizations and human groups". (Cristea, 2015)

At the beginning of the $20^{\text {th }}$ century, in the domain of economic sciences, a new concept appears, namely that of management, with a rather difficult and somewhat controversial start because it tended to create confusion, to replace the concept of leadership, be synonymous with it, be in the part-whole relationship with it, be defined as an art or as a science, be at the crossroads of the two. When the literature began individualizing leaders and managers by means of features, traits necessary in performing/exerting functions specific to each of them at organizational level, the ambiguity was even higher. And as if this state were not enough, some authors in their work make the difference between "personal leadership and managerial leadership, the former referring to the person who is naturally born with the leadership gift, and the latter being able to learn it", which means that a leader cannot be a manager and the other way round. (Zlate, 2007, p.1)

Other specialists dissociate management in the science of management and scientific management, considering that only a part of the managers' work has a scientific component, and the other part belongs to the empirical, to the experience and flair in business (Zorlențan et al., 1998), (Nicolescu \& Verboncu, 2008) and (Burduş, 2017). Zlate (2007, p.1), make and interesting synthesis of the specialized literature, identifying 3 situations related to the way in which the concepts of leadership and management are used, namely:

1. The two concepts are synonymous. In the author's opinion, "such an operational approach appears especially in those cultures where there are no separate terms in the language to name the two realities." (Zlate, 2007, p.1)

2. The differentiation between the two concepts. It appears that Zaleznik (1977) was the first author who made the major difference between managers and leaders, according to a set of criteria among which there are: the purpose they have, their perspective on work, their relationships with others and their self-perception. Essential contributions in the domain are made by Warren Bennis, considered a pioneer of contemporary studies in the field of 
leadership, alongside authors from the French school. According to this philosophical trend, leadership is "more frequently associated with the cognitive, imaginative, anticipative dimension, whereas management is associated with the action dimension." (Zlate, 2007, p.1)

3. The part-whole relationship, leadership being considered the essential part of management. The origin of this perspective is in the work of Henry Fayol (1916) who considered leadership a component of general administration (management). Steven Kerr (1973) quoted in Zlate (2007, p.1) refers to leadership as a "subset of managerial behavior", leadership being only one of the ways in which management ensures organizational efficiency. Also, Elliot Jaques and Stephen Clement (1994) consider that leadership existing in the managerial activity is a major factor in business competitiveness and effectiveness, opinion which was later embraced by many authors, including Romanian authors (Nicolescu \& Verboncu, 2008) and (Burdus,, 2017). We embrace this point of view in this research.

Numerous specialists (Blanchard, 2011; Collins, 2010; Griffin, 2014; Kohn \& O`Connell, 2011) approach management and leadership from a modern perspective, the models they proposed being the result of studies, research performed on organisations and their leaders, as well as the result of their personal experience in business. Blanchard (2011), for example, speaks about top management, leadership and the establishment of high performing organizations, relying on his personal experience in his own international management training and consulting company and, at the same time, as a professor and member in the university board of directors. In his approach, "High Performing Organizations (HPO) are enterprises which, in time, continue to achieve remarkable results, while maintaining the highest level of human satisfaction and the determination to be successful". Together with a team of researchers, he creates the HPO SCORES model. "SCORES is an acronym which represents the six elements found in a high performing organization, namely:

- $\quad \mathrm{S}=$ Shared Information and Open Communication

- $\quad \mathrm{C}=$ Compelling Vision

- $\mathrm{O}=$ Ongoing Learning

- $\quad \mathrm{R}=$ Relentless Focus on Customer Results

- $\quad \mathrm{E}=$ Energizing Systems and Structures

- $\quad \mathrm{S}=$ Shared Power and High Involvement" (Blanchard, 2011)

Burduş (2017) analyzes management and leadership aspects historically, identifies two components of leadership (strategic and human components), places leadership in business, groups companies according to their leadership competence and concludes that "leadership is not something different from management, an activity performed in parallel with management, but management in which more emphasis is placed on the human side, on the relationships between managers and subordinates, and, generally, on the relationships between an organization's employees and the personal traits of the managers who ensure them a wider vision".

\section{RESEARCH METHODOLOGY}

The research performed if of empirical type, based on direct observation of reality, starting from theoretical concepts and models. The research complies with qualitative research criteria as defined in the specialized literature. Qualitative research (Chelcea, 2009) "means the empirical research within socials and human sciences displaying a number of five characteristics: 1) the research is performed mainly from a comprehensive perspective; 2) it approaches the object of 
study in and open and highly comprehensive manner; 3) it includes data gathered using qualitative methods, namely by means of methods which do not involve any quantification; 4) it analyses the data qualitatively, meaning that words are analyzed directly by means of using other words, without using a counting operation; 5) in the end, it leads to a story or to a theory, not to a demonstration".

In this sense, we studied the classical and contemporary literature relevant to the field of organizational theories, management and leadership, giving priority to novelty elements, yet without ignoring fundamental concepts. The sources were selected according to the relevance criterion, with emphasis on publications in the fields of management and organizationalmanagerial psychology, because, in our opinion, the central, essential element at society level in general and at organization level in particular is human being, regardless of the role he/she may have in an organization, respectively owner, manager (top, middle, lower level) or operatives. Therefore, it is important to investigate the concepts provided by psychology in general and organizational-managerial psychology in particular, the latter being the science which studies the relationships between human being and organization and, in a narrow sense, the relationships between managers and operatives. Moving forward with this line of thought, from an economic point of view (in terms of result indicators), an essential element is represented by the effects of the relationships between managers and operatives, between managers and managers on the horizontal and vertical line of the management systems, as well as between operatives and operatives, on organizational performance.

Also, based on the dynamic analysis of the main indicators in the financial records of certain economic agents and public institutions, of their periodical public reports, as well as from direct observation and personal experience in the field of high-level academic management, I considered it a scientific challenge to initiate a study on the possible projection of a new situational management model mainly based on correlating the result indicators with organizational and managerial competence (implicitly the definition of competence indicators) and the (re)structuring of organizations along three lines with very well-defined roles and responsibilities, actually, the application of the governance model and of the three lines of defence at organizational level.

At this stage, the empirical research confirms the scientific intent, outlines the new model of situational management, the authentic manager's profile (emotionally intelligent leader), defines the organizational and managerial competence indicators and opens the horizon to a future theoretical fundamental research related to this topic.

\section{DISCUSSIONS}

In this research paper, the organization is defined according to DEX (1998), considered legal entity, analyzed as system in general and as psychosocial system in particular, a selfregulating one, where cognitive processes are considered essential to the construction, reconstruction, development and longevity of the organization.

Also, the premises of the scientific endeavor are the following:

$\checkmark$ There is no universally valid truth, no absolute truth.

$\checkmark$ The principles of adaptation, survival and evolution are the only principles accepted beyond any doubt.

$\checkmark$ There are no universally valid models, mechanisms for designing an organization's management, control, governance and leadership system, whose implementation will 
guarantee the efficient operation, organizational success being defined by means of economic, financial and managerial performance. The same model, the same mechanisms for designing, organizing, management, control, regulation, governance and leadership are unequally efficient/effective according to the (institutional/organizational, national and international, as the case be) context in which the organization operates.

$\checkmark$ In order for the analyses which result in the generation of ideas, theories, models to have scientific value, they must focus on organizations in the same sector/domain of activity, with the same opportunities, with relatively similar resources, active in comparable environments and positioned similarly in their lifecycle.

In characterizing contemporary organizations, we need to consider the main changes which have occurred in the past years, namely:

$\checkmark$ decreasing the number of hierarchical levels, rendering organizational structures flexible and increasing the degree of adaptability to change;

$\checkmark$ increasing employees' mobility (their stability and need to belong to a group have decreased considerably);

$\checkmark$ the human resource is detached from the organization where it is employed (we identify in this sense a low level of organizational commitment), from its mission and values (only at declarative level things are quite the opposite!)

$\checkmark$ (re)defining motivational needs for self-realization, esteem, social status almost exclusively based on earned individual incomes, in this context, presence in an organization depending on the convergence of personal and organization interest. A solid argument in this sense is the reality supported by statistics: persons who work in domains which are entirely different from their competence domain (graduate program) - doctors working in sales, real estate, transports, etc., electronical engineers employed in financial consulting, trade, etc., economists being active on the European market in cleaning services, taxi services, hotel maids or receptionists, etc. stability no longer characterizes experienced age groups (50-year olds and over), the balance leaning towards change in employment, including change in domain if they earn incomes which are compatible with their expectations/needs.

The management process at organizational level is performed in a differentiated manner, according to managerial competence. In this context, we characterize two types of managers authentic and conjectural ones - in a simplified way, reduced to "knowing" or "not knowing", starting from "postulating cognition - as fundamental factor - generating and explaining the entire organizational life". (Zlate, 2008, p. 2). Certainly, this situation is presented only as a theoretical starting point, as, in actual practice, there are no absolute situations, of the "perfect" or "imperfect" type, yet, between the two opposites, there are forms that lead to a high-performing or underperforming management (proven through results, mainly the economic-financial results as they are documented in the financial-accounting records).

Consequently, we consider that a conjectural manager does not know how to:

$\checkmark$ efficiently manage the available resources and at the same time identify new resources (here we refer to the efficient administration of resources to the interest of the respective organization, in order to achieve its strategic objectives, missing and goal for which it was set up!);

$\checkmark$ correctly position the organization in its lifecycle and adopt an adequate strategic management behavior; 
$\checkmark$ be aware of the fact that efficient management depends on the quality of the interaction between manager and subordinates (members of the respective group/organization);

$\checkmark$ determine and maintain the group structures congruence at an optimum level;

$\checkmark$ define, estimate and shape the organizational competence and intelligence coefficient of the organization they run;

$\checkmark$ differentiate task performance from contextual performance;

$\checkmark$ integrate in the organizational culture the performance-generating trinoma, namely culture of discipline, culture of responsibility and culture of quality (defined first of all through professional and moral competence);

$\checkmark$ ensure the convergence of strategic management and operational management;

$\checkmark$ be aware that the API trinoma (attitude - power - influence) may have a positive impact, but also a negative one, on the organization's balance and performance;

$\checkmark$ adopt a behavior based on respect at organizational level;

$\checkmark$ not to deal with exceptions, with those who are exempt from the system of values, regulations and rules;

$\checkmark$ implement a management style which is balanced, differentiated according to results, the level of employee commitment to achieving individual goals, etc. (a set of criteria is recommended), understanding the authoritarian style is an aggressive management style, unacceptable in a democratic, developed and evolved society, that using it means a type of feudalism which is not even beautified, which has negative effects on the employees' morale, on their emotional balance (in organizational-managerial psychology there are studies, ample research on the effects of employing different managerial styles and, not less importantly, studies dedicated to organizational pathology);

$\checkmark$ integrate the concept of risk in the strategic management of the organization they run;

$\checkmark$ adopt a management style adequate for the organizational context, differentiated according to the degree of the relative maturity of the group members and to the overall groups' (academic and emotional) intelligence coefficient (in other words, to adapt the management style to the organization's development level);

$\checkmark$ (re)design an efficient management system, create a visionary organization which can operate also after the term of office/the agreement expires.

An authentic (professional/competent) manager is at the opposite end, "knowing how to ..." (efficiently manage the resources, correctly position the organization in its lifecycle, etc. Additionally, the authentic, competent, educated and rational manager will be focused on results, without implementing the principle according to which "the end justifies the means", will not be conflictual (will not trigger, now encourage conflicts within the organization), will always substantiate their speech, will have arguments, will not accept a hostile dialogue and will try to set relationships correctly, honestly with others (peers and subordinates). They will be aware of the fact that the organization creates the organizational individual and that a certain behavior accepted within the organization will generate similar behavior outside the organization, which means that values (or nonvalues) will propagate at society level. Here is yet another type of management and leadership responsibility!

The authentic manager is not by far a projection of perfection. They will certainly make errors in exerting their managerial prerogatives, they will display managerial behaviors which may not always be adequate, make decisions at unfavorable moments with negative effects, either in financial terms, or in emotional terms, on their colleagues, peers, employees, team members, etc., yet, unlike the conjectural leader, they will acknowledge 
their own limits and will accept their potential management and/or leadership errors and those of managerial behavior.

In conclusions, in an (apparently) simplified form, the authentic manager must not be an incompetent, amorphous and duplicitary character.

\section{CONCLUSIONS}

The argument for authentic management and emotionally intelligent leaders brings us to the conclusion that, at present, there is a need to create a tool with allows for the quantification of managerial performance and for outlining a new situational management model based on correlating result indicators with organizational and managerial competence.

The new construct observes an established principle in the specialized literature, according to which management is always relative to the situation, and wants to be a model of management with leadership and emotional intelligence components, referring mainly to the manager's adapting the management style and the way the management process unfolds to the level of development of the organization they run, level which targets:

$\checkmark$ positioning the company in its lifecycle (start, development, maturity, decline);

$\checkmark$ the business scale (company size, market on which it activates - local, regional, national, international);

$\checkmark$ the value of the organizational competence indicator (complex indicator, global/generally dynamic indicator, which has in its structure the specialized knowledge, academic intelligence, emotional intelligence and other elements, an indicator which is defined differently according to managerial and operational positions, the managerial positions in their turn being differentiated according to management levels, positions considered strategic and non-strategic, etc.);

$\checkmark$ the value of the organizational commitment index (with major impact on performance, because the organization which has a high level of organizational competence, especially in terms of strategic positions, will not necessarily be a high-performer in case the organizational commitment index is decreased, as the employees have the competence but are not (any longer) willing to use it within the organization except at the level at which their job is not in danger, their position in the organization is not affected, namely they perform their job-related duties strictly, at a minimum performance level without being creative, a situation which generates a type of organizational apathy);

$\checkmark$ the organization's external power or response capacity in the face of threats and opportunities from the external environment.

The model envisages top management, namely the level at which strategic decisions are made, being applicable within organizations whose owners want them to be high-performers and long-established at the same time. In other words, if the business owners want conjectural profit, then they will not invest in creating an intelligent organization which is highperforming on the long term. They will focus on the business opportunity, according to which they will set up and close companies over short periods of time, which is why leadership will only be transactional - the owners want to make profit by paying a (negotiated) salary to employees who are profitable (through the activity they perform within the organization they earn their salary and bring added income to the owners). In this case we cannot speak about investment in the human resource, about the owners' interest in determining the motivationalattitudinal structure within the organization, the group congruence indicators, the elaboration of human resources policies focused on personal development and career management, the 
top management's interest in implementing established management models and methods, etc.

In conclusion, the new model of contextually applied management is an attractive intellectual concept, which future research will validate, improve or invalidate.

\section{REFERENCES}

Academia Română, Institutul de Lingvistică "Iorgu Iordan". (1998). Dicționarul Explicativ al Limbii Române (DEX). Ediția a II-a. București: Editura Univers Enciclopedic

Bar - On, R. \& Parker, J. (2011). Manual de inteligență emoțională: teorie, dezvoltare, evaluare și aplicații în viața de familie, la școală și la locul de muncă. Trad: Cork, A.; București: Curtea Veche Publishing

Bennis, W. \& Nanus, B. (2000). Liderii. Strategii pentru preluarea conducerii. București: Business Tech International Press

Blanchard, K. (2011). Conducerea la un nivel superior: Blanchard despre leadership și crearea unor organizații de inaltă performanță. Trad: Bujor, C.; București: Editura Meteor Press

Burduș, E. (2017). Tratat de management. Ediția a III-a. București: Editura Pro Universitaria

Chelcea, S. (2009). Metodologia cercetării sociologice. Metode cantitative și calitative. Ediția a III-a. București: Editura Economică

Collins, J. (2010). Excelența în afaceri. București: Editura Curtea Veche

Cristea, D. (2015). Tratat de psihologie socială. București: Editura Trei

Griffin, R. (2014). Fundamentals of Management. Seventh Edition. USA: South - Western, Cengage Learning

Jacques, E. \& Clement, S. D. (1991). Executive Leadership. A Practical Guide to Managing. Cambridge: Basil Blackwell Inc.

Kohn, S. \& O`Connell, V. (2011). 6 obiceiuri ale celor mai eficienți manageri. București: Editura Curtea Veche

Nicolescu, O. \& Verboncu, I. (2008). Fundamentele managementului organizației. București: Editura Universitară

Plane, J. M. (2000). Théories des organisation. Paris: Dunod

Zaleznick, A. (1977). Managers and Leaders: Are They Different? In Harvard Business Review, January 2004 Issue, from https://hbr.org/2004/01/managers-and-leaders-arethey-different

Zlate, M. (2007). Tratat de psihologie organizațional - managerială. Volumul 2. Iași: Editura Polirom

Zlate, M. (2008). Tratat de psihologie organizațional - managerială. Volumul 1. Iași: Editura Polirom

Zorlențan, T., Burduș, E. \& Căprărescu, G. (1998). Managementul organizației. București: Editura Economică 